\title{
Mapping of the human insulin receptor substrate-2 gene, identification of a linked polymorphic marker and linkage analysis in families with Type II diabetes: no evidence for a major susceptibility role
}

\author{
K. Kalidas ${ }^{1}$, J. Wasson ${ }^{1}$, B. Glaser ${ }^{2}$, J.M. Meyer ${ }^{3}$, L. J. Duprat ${ }^{3}$, M. F.White ${ }^{4}$, M. Alan Permutt ${ }^{1}$ \\ ${ }^{1}$ Division of Metabolism, Endocrinology and Diabetes, Washington University Medical School, St. Louis, Missouri, USA \\ ${ }^{2}$ Department of Endocrinology and Metabolism, Hebrew University Hadassah Medical Center, Jerusalem, Israel \\ ${ }^{3}$ Millennium Pharmaceuticals, Inc., Cambridge, Massachusetts, USA \\ ${ }^{4}$ Research Division, Joslin Diabetes Center, Boston, Massachusetts, USA
}

\begin{abstract}
Summary Insulin receptor substrate 2 (IRS-2) is a substrate of the insulin receptor and mediates the action of the insulin. Disruption of the IRS-2 gene in mice results in peripheral insulin resistance and relative insulin deficiency. It is therefore possible that defects in the IRS-2 gene contribute to Type II (non-insulin-dependent) diabetes mellitus. We have examined the gene for evidence of linkage to Type II diabetes in Ashkenazi Jewish families. Radiation hybrid panel mapping was used to refine the map position of the IRS-2 gene and, in the absence of polymorphic markers within the gene, to identify nearby markers. The IRS-2 gene was placed $23 \mathrm{cR}$ from the marker
\end{abstract}

D13S1265 on chromosome 13q34. 200 affected sibpairs were genotyped for three markers across the region. Nonparametric linkage analysis (GENEHUNTER) used with this data found no evidence of excess allele sharing in the IRS-2 gene region. We therefore concluded that variation in the IRS-2 gene is unlikely to contribute to Type II diabetes in this discrete Caucasian population. [Diabetologia (1998) 41: 13891391]

Keywords IRS-2 gene, microsatellite marker, radiation hybrid (RH) mapping, affected sib-pair analysis, Ashkenazi Jews, Type II diabetes
The insulin receptor substrates are intracellular proteins that are phosphorylated by the insulin receptor and mediate the actions of insulin. Insulin receptor substrate (IRS)-1 has been well characterized and shown to mediate several cellular responses including mitogenesis, protein synthesis and glucose transport during insulin stimulation [1]. Consequently, IRS-1 represented a candidate gene for insulin resistance in Type II (non-insulin-dependent) diabetes mellitus. Although variants in the IRS-1 gene were described, these mutations only accounted for a small proportion of Type II diabetes [2]. Disruption of the IRS-1

Received: 19 March 1998 and in revised form: 15 June 1998

Corresponding author: M. A. Permutt, M.D., Division of Endocrinology, Diabetes, and Metabolism, Washington University School of Medicine, 660 South Euclid, Campus Box 8127, St. Louis, MO 63110, USA

Abbreviations: cM, Centimorgan, IRS, insulin receptor substrate; LOD, logarithm of odds; NPL, non parametric linkage; $\mathrm{PCR}$, polymerase chain reaction. gene in mice resulted in mild insulin resistance with normal basal glucose concentrations and fasting hyperinsulinaemia [3]. Diabetes did not develop at any time in the IRS-1 deficient mice. Concomitantly, another protein was discovered as an interleukin (IL) 4 receptor substrate and was subsequently found to be an insulin receptor substrate also phosphorylated in the IRS-1 deficient mouse. This protein was designated as IRS-2 [4]. It has been suggested that the insulin resistance caused by the absence of IRS- 1 may be compensated through IRS-2 and high insulin production, resulting in a non-diabetic phenotype [1].

Recent studies have shown that homozygous disruption of the IRS- 2 gene in mice resulted in a novel phenotype that differed from that of IRS-1 deficient mice. Deficiency of IRS-2 was associated with peripheral insulin resistance and with hypoinsulinaemia and relative islet beta-cell failure [5]. Mice deficient in IRS-2 displayed progressive deterioration of glucose homeostasis and overt diabetes with increasing fasting hyperglycaemia. These observations suggested that functional defects in IRS-2 may contribute to 
Type II diabetes by combined defects in insulin production as well as in insulin action.

Type II diabetes is a complex multifactorial disorder whose mode of inheritance is not established. Nonparametric linkage analysis, where no assumptions are made for variables such as mode of inheritance, disease frequency and penetrance, was done using the program GENEHUNTER to identify excess allele sharing in the region of the IRS- 2 gene. In this study we have mapped the human IRS-2 gene and defined a nearby polymorphic marker. Three markers spanning a 16.9 centimorgan $(\mathrm{cM})$ region flanking the IRS-2 locus were used for linkage analysis in families of Ashkenazi Jewish origin with Type II diabetes.

\section{Subjects and methods}

Subjects. The study sample included 150 families of Ashkenazi Jewish origin with at least one sib-pair presenting with Type II diabetes. Ashkenazi Jewish descent was defined as having all four grandparents born in, or descendent from ancestors born in any of the countries of Eastern Europe. Diabetes was defined according to WHO criteria [6]. Late onset Type I (insulin-dependent) diabetes mellitus was avoided by including only patients who had been treated by diet alone or oral agents for at least 2 years after diagnosis. These criteria, combined with the low relative incidence of Type I diabetes in this population should result in a very low rate of incidence of Type I diabetes among study subjects. Since the genetic component of Type II diabetes is greater in relatively early onset disease, we only included families in which at least one affected sibling was diagnosed with Type II diabetes before the age of 55 years. Furthermore, in order to enhance the phenotypic similarity of disease within the families, the difference in age at diagnosis of diabetes in any sib pair had to be less than 10 years. The likelihood of bilineal inheritance was decreased by excluding families in which both parents were known to have diabetes. DNA was isolated from peripheral blood lymphocytes using the Puregene kit (Gentra Systems Inc., N.C., USA). The project was approved by the ethics committees of Washington University School of Medicine and Hadassah University Hospital and written informed consent was obtained from all subjects.

Radiation hybrid mapping. The Stanford G3 panel (Research Genetics, Huntsville, Ala., USA) was screened in duplicate by polymerase chain reaction (PCR) amplification (annealing temperature $56^{\circ} \mathrm{C}, \mathrm{MgCl}_{2}$ concentration $1.5 \mathrm{mmol} / \mathrm{l}$ ) with primer sequences $5^{\prime}$-GCCGCAACCGCCGCGGCTCG-3" (forward) and 5'-GCGGCCGCGCGGCC CTCGCTGACC3 ' (reverse) of the IRS-2 gene. The PCR products were analysed on agarose gels (Life Technologies Inc, Gaithersburg, Md., USA) and results were submitted to the Stanford Human Genome Center for linkage analysis.

Genotyping. The regions containing D13S1265 and two flanking markers, D13S286 and D13S285, were amplified by PCR using primer sequences published by Genethon (http:// www.genethon.fr/genethon_en.html). Genomic DNA (100 ng in $10 \mu \mathrm{l}$ reactions) was amplified (annealing temperature $55^{\circ} \mathrm{C}, \mathrm{MgCl}_{2}$ concentration of $1.5 \mathrm{mmol} / \mathrm{l}$ ) with $1 \mathrm{Ci}\left[\alpha-{ }^{33} \mathrm{P}\right]$ dATP at $1000 \mathrm{mCi} / \mathrm{mmol}$ (NEN, Life Science Products, Boston, Mass., USA). The PCR products $(3.5 \mu \mathrm{l})$ were electrophoresed on $6 \%$ denaturing polyacrylamide gels (Fisher Scientific,
Table 1. Microsatellite markers across chromosome 13q34 used for linkage analysis of the IRS-2 gene region, heterozygosity of markers, genetic distance in cM from the pter, cumulative NPL scores and $p$ values for multipoint GENEHUNTER analysis

\begin{tabular}{llcrl}
\hline Marker & $\begin{array}{l}\text { Hetero- } \\
\text { zygosity }\end{array}$ & $\begin{array}{l}\text { Genetic } \\
\text { Distance }\end{array}$ & $\begin{array}{l}\text { NPL } \\
\text { score }\end{array}$ & $\begin{array}{l}p \\
\text { value }\end{array}$ \\
\hline D13S286 & 0.76 & 95.9 & -0.63 & 0.45 \\
D13S1265 & 0.80 & 101.7 & 0.45 & 0.32 \\
D13S285 & 0.81 & 112.8 & 0.29 & 0.33 \\
\hline
\end{tabular}

Table 2. Exclusion values from Mapmaker/SIBS for microsatellite markers in the IRS-2 gene region

\begin{tabular}{llll}
\hline Marker & \multicolumn{3}{l}{ MLS $^{\mathrm{a}}$ at $\lambda_{\mathrm{s}}$} \\
\cline { 2 - 4 } & 1.5 & 1.7 & 2.0 \\
\hline D13S286 & -3.47 & -4.99 & -7.15 \\
D13S1265 & -1.27 & -2.26 & -3.76 \\
D13S285 & -1.64 & -2.67 & -4.22 \\
\hline
\end{tabular}

${ }^{a}$ MLS, maximum LOD score

N.J., USA) and autoradiographed (Hyperfilm MP, Amersham, Arlington heights, Ill., USA). Control DNA of people from the Centre d'Etude du Polymorphisme Humain database was included in each gel. Alleles were read double blind.

Statistical analysis. Nonparametric multipoint linkage analysis was done using the program GENEHUNTER [7] to test for linkage in the IRS-2 gene region. Genotype data from 200 affected sib pairs were used in the analysis. Marker allele frequencies were estimated from unrelated study subjects. Multipoint sib-pair exclusion mapping, using all possible sib-pairs, was carried out with Mapmaker/SIBS [8] for arbitrarily chosen $\lambda_{\mathrm{s}}$ values ranging from 1.5 to 2.0 .

\section{Results}

Mapping with radiation hybrid panels placed the IRS-2 gene $23.6 \mathrm{cR}$ from the microsatellite D13S1265 on chromosome 13q (Logarithm of odds [LOD] score $>3$ ). According to Genethon, D13S1265 maps to $101.7 \mathrm{cM}$ from the top of chromosome 13. The maximum nonparametric linkage (NPL) score obtained from multipoint analysis of the IRS-2 gene region with GENEHUNTER was $0.45(p=0.32)$ (Table 1$)$ indicating no excess of allele sharing across the IRS-2 gene region. Exclusion analysis with Mapmaker/SIBS (Table 2) indicated that all three markers in the region could be excluded for $\lambda_{\mathrm{s}}$ value of 1.7 or more (LOD scores $<-2$ ). Marker D13S1265 could not be excluded for a $\lambda_{\mathrm{s}}$ value of 1.5.

\section{Discussion}

To assess the possible involvement of the IRS-2 gene in susceptibility to Type II diabetes, linkage analysis was done by genotyping Ashkenazi Jewish families. 
Ashkenazi descent was defined as the subset of Caucasian Jews from Poland, Russia, Rumania, Germany and other Eastern European countries. This ethnic group was chosen because of its relative genetic homogeneity, as evidenced by the occurrence of founder mutations for a number of inherited diseases [9].

The organization of the human IRS- 2 gene has recently been defined [4]. It consists of a single exon that was mapped to chromosome $13 \mathrm{q} 34$ by fluorescent in situ hybridization [10]. The gene does not contain polymorphic microsatellite markers which could be used in linkage analysis. We therefore have used radiation hybrid mapping with the Stanford G3 panel to uniquely place the gene within a framework of polymorphic markers. Results obtained from hybrid panel mapping enabled us to select microsatellite markers across a $16.9 \mathrm{cM}$ region of chromosome $13 q 34$ to be used in linkage analysis of the IRS-2 gene region. The NPL scores from nonparametric linkage analysis did not show a significant increase in allele sharing across the IRS-2 gene region. Exclusion analysis showed that linkage could not be excluded at a $\lambda_{\mathrm{s}}$ of 1.5 for the marker linked to the IRS-2 gene. Our data excludes a major role for this gene in susceptibility to Type II diabetes in Ashkenazi Jews. The possibility of a minor role of the IRS-2 gene in a polygenic model, however, cannot be excluded, likewise the contribution of this gene to diabetes in other racial and ethnic groups, or in other forms of diabetes such as MODY. Although the results of these studies do indicate that there is no variation within the immediate region of the IRS-2 gene controlling expression, they do not eliminate the possibility of changes in expression of an otherwise normal IRS-2 protein due to mutations in genes responsible for mediation of IRS-2 expression.
Acknowledgements. We would like to express our deep appreciation to the participants of this study. We thank M. Ohayon, M. Slatsky, and R. Y. Zisk, for their tireless efforts in recruiting and researching the Israeli diabetic patients and their families and J. Wokurka for her help in preparation of the manuscript. We acknowledge Millennium Pharmaceuticals and HoffmanLa-Roche for a joint research grant and research grants from the National Institutes of Health (DK49583 and DK16746, MAP).

\section{References}

1. Yenush L, White MF (1997) The IRS-signaling system during insulin and cytokine action. BioEssays 19: 491-500

2. Almind K, Bjorbaek C, Vestergaard H, Hansen T, Echwald SM, Pedersen O (1993) Amino-acid polymorphisms of insulin receptor substrate-1 in non-insulin-dependent diabetes mellitus. Lancet 342: 828-832

3. Araki E, Lipes MA, Patti ME, et al. (1994) Alternative pathway of insulin signaling in mice with targeted disruption of the IRS-1 gene. Nature 372: 186-190

4. Sun X J, Wang L M, Zhang Y, et al. (1995) Role of IRS-2 in insulin and cytokine signaling. Nature 377: 173-177

5. Withers DJ, Gutierrez L, Towery H, et al. (1998) Disruption of IRS-2 causes type 2 diabetes in mice. Nature 391: 900-903

6. World Health Organization Study Group Diabetes Mellitus (1985) Technical report series No. 727, WHO, Geneva

7. Kruglyak L, Daly MJ, Reeve-Daly MP, Lander ES (1996) Parametric and nonparametric linkage analysis: a unified multipoint approach. Am J Hum Genet 58: 1347-1363

8. Kruglyak L, Lander ES (1995) Complete multipoint sibpair analysis of qualitative and quantitative traits. Am J Hum Genet 57: 439-454

9. Jorde L (1992) Genetic diseases in the Ashkenazi population: Evolutionary considerations. In: Bonne-Tamir B, Adam A (eds) Genetic Diversity among Jews: Diseases and Markers at the DNA Level. Oxford University Press, New York, pp 305-318

10. Bernal D, Almind K, Yenush L et al. (1998) Insulin receptor substrate-2 amino acid polymorphisms are not associated with random type 2 diabetes among Caucasians. Diabetes 47: 976-979 